\section{Concepts of animal behaviour}

\section{Aubrey Manning}

Introduction to Ethology. By K. Immelmann. Pp.237. (Plenum: 1980.) $\$ 22.50, £ 14.18$.

IMMELMANN defines ethology as "the study of the biology of behaviour". This covers almost everything, but whilst I am no longer convinced that ethology as a separate field exists, it remains easy to recognize the influence of the ethological approach in all branches of behavioural science. Certainly, we need textbooks which introduce ethological concepts, particularly as so many students are now plunged directly into elaborate sociobiological arguments and tend to give short shrift to the study of an individual's behavioural organization and development, which has always been ethology's strong point. The translation of Immelmann's book is going to be useful for it covers a lot of ground.

My heart sank at first when I saw, yet again, illustrations of Tinbergen's herringgull bill patterns and stickleback models. Yet there are also plenty of fresh examples and it is healthy to have many from the German literature. Anyway there is nothing to say that old examples (or old concepts) are not still the best, provided that, where necessary, they are reinterpreted in the light of modern thinking.
I do feel Immelmann falls short here in some cases, for example when describing the effects of the hawk-goose silhouette on game birds or when discussing terms like "action-specific energy" as causal factors in behaviour.

From a student's point of view the book is clearly set out, with sensible use of subheadings. Systematization is taken too far in places, with Immelmann's excessive use of formal terms to classify his material. Some of these, such as "ethoendocrinology" and "acquired releasing mechanism (ARM)", are unlikely to be encountered again outside the pages of this book.

I would have liked more examples to be spelt out in detail, but Immelmann has a large field to cover and in general he summarizes very clearly. The chapter on social behaviour is particularly valuable as a modern re-statement of the ethological approach with due emphasis on sexual behaviour and care of the young. In summary, a good book to work through with students on an introductory animal behaviour course.

Aubrey Manning is Professor of Natural History at the University of Edinburgh, where he works on and teaches animal behaviour. He is author of An Introduction to Animal Behaviour (Edward Arnold, 3rd Edn, 1979).

\title{
Primates in the lecture theatre
}

\section{W.C. McGrew}

Social Behaviour in Primates. By Neil Chalmers. Pp.256. (Edward Arnold/University Park Press: 1980.) Flexi £6.50, $\$ 19.95$.

THE rise of behavioural studies of nonhuman primates over the past two decades has stimulated a concomitant growth of university courses, especially in North America. Because of their crossdisciplinary nature, such courses are taught in departments of anthropology, biology, and psychology, thus creating a large market for textbooks. The first wave of such books appeared in the early 1970s, Jolly's Evolution of Primate Behavior (Macmillan, 1972) and Rowell's Social Behaviour of Monkeys (Penguin, 1972), for example, but these are obsolescent.

Now comes a new entry into the area, written by an English primatologist experi-

Twelve years after the appearance of the second edition, Cambridge University Press have published a new edition of Excursion Flora of the British Isles by A.R. Clapham, T.G. Tutin and E.F. Warburg. The new edition is available with a plastic cover and costs $£ 12.50$. enced in African field-studies. The substance of the book is in six chapters on groups, social structure, infant development, sex, dominance and adaptiveness. It focuses on fieldwork but calls in laboratory studies when appropriate, for example on hormonal effects. The approach is selective rather than encyclopaedic, and one of the author's strengths is his skill in choosing apt examples. The most serious drawback is that consideration of the function of behaviour is postponed until the final quarter of the text. What precedes is solid discussion of the causation of behaviour, but until the end there are no hooks upon which the reader can hang the obvious questions which this discussion stimulates. For example, why should primates live in groups, unlike many other mammals? Why do some, but not all, primates breed seasonally?

Still, these are but quibbles, as Chalmers has produced an admirably lucid textbook which deserves to be widely used.

W.C. McGrew is a Lecturer in Psychology at the University of Stirling and a Visiting Faculty Member of the University of North Carolina at Charlotte.

\section{More neuroscience}

Trevor W. Robbins

Behavioral Neuroscience: An Introduction. By C. W. Cotman and J. L. McGaugh. Pp.838. (Academic: 1980.) $\$ 21.95, £ 13.80$. Physiological Psychology. By T. S. Brown and P. M. Wallace. Pp.634. (Academic: 1980.) \$20.95, £11.20. Fundamentals of Human Neuropsychology. By B. Kolb and I. Q. Whishaw. Pp.501. (W. H. Freeman: 1980.) \$17.95, $£ 8.95$.

"How could anyone know enough to write a whole textbook?" Brown and Wallace thus modestly quote one of their own students in the preface to Physiological Psychology. Indeed, the sometimes dazzling technical advances in neuroscience have led to a proliferation in knowledge which defies the capacity of individual writers to achieve the degree of synthesis or balance required of a text. Brown and Wallace's book, however, is but one in a long line of such attempts and so it seems reasonable to consider some criteria by which textbooks in this area can be assessed.

One of my own criteria is to ask whether it is possible to guess from the relative qualities of the various sections, the specific research interests of the authors. I concluded (partly correctly) from Physiological Psychology that one or other of its authors had special expertise in the chemical senses, sexual motivation or circadian rhythms, since these sections seemed the most detailed and bestexplained.

Most of the other topics covered fit into the familiar organization of chapters on introductory neuroanatomy and neurophysiology, sensory systems, motor systems, neural plasticity, learning and memory, and "higher processes". These subjects are generally covered adequately, but suffer from temptations seldom avoided by textbook writers in physiological psychology.

The first of these is to act essentially as an uncritical, passive reporter of what are considered to be main issues or experiments. For instance, Brown and Wallace's discussion of hunger and satiety flits uneasily between the vagaries of "central" and "peripheral" theories, for example, "But as we shall see later in this section, the pendulum is swinging back again, and is now somewhere in the middle"' (p.291). Now this may be an accurate assessment of the state of that particular art but this lack of intellectual guidance would not instil me, nor I suspect, an undergraduate, with much confidence.

A second, related temptation is to avoid such shows of indecision by skirting any real discussion of the questions posed, or of the nature of the underlying processes. Thus, an otherwise tidy account of "brain stimulation reward" is marred by a meagre half-page of theoretical discussion of 